\title{
Be Your Best You: A Pilot Study of a Positive Psychology Programme for People with Depression, Anxiety or Stress in Greece
}

\author{
Kotsoni Aikaterini, Kanellakis Konstantinos, Stalikas Anastasios \\ Department of Psychology, Panteion University of Social and Political Sciences, Athens, Greece \\ Email:kotsonikaterina@gmail.com
}

How to cite this paper: Aikaterini, K., Konstantinos, K., \& Anastasios, S. (2020). Be Your Best You: A Pilot Study of a Positive Psychology Programme for People with Depression, Anxiety or Stress in Greece. Psychology, 11, 13-29.

https://doi.org/10.4236/psych.2020.111002

Received: November 29, 2019

Accepted: December 30, 2019

Published: January 2, 2020

Copyright ( 2020 by author(s) and Scientific Research Publishing Inc. This work is licensed under the Creative Commons Attribution International License (CC BY 4.0).

http://creativecommons.org/licenses/by/4.0/

\begin{abstract}
This pilot study aimed to design a Positive Psychology programme for depression, anxiety or stress and test its effectiveness among Greek Psychology students. Twenty-six participants with severe or very severe symptoms of depression, anxiety or stress were assigned to the intervention and control groups. Participants in the intervention group attended six weekly sessions of the Be Your Best You Programme. All participants completed self-report questionnaires (Depression, Anxiety and Stress Scale, Positive and Negative Affect Scale, Satisfaction with Life Scale) when the programme started and on the completion of the six-week intervention programme. The results indicated significant decreases in depression, anxiety, stress, and negative emotions, as well as increases in satisfaction with life among the people who attended the programme. Our findings suggest that a programme consisted of evidence-based Positive Psychology interventions could be offered to people suffering from depression, anxiety or stress to managing their difficulties. Further studies are required in this field to establish Positive Psychology intervention as a treatment of choice.
\end{abstract}

\section{Keywords}

Positive Psychology Interventions, Anxiety, Depression, Well-Being

\section{Introduction}

According to the World Health Organization (2017), one out of three Europeans will be affected by a mental health disorder during their lifetime. Mental health issues are a leading threat to our well-being; with depression and anxiety being the most diagnosed disorders. Nowadays, we have more effective psychological 
therapies than ever before for the treatment of these disorders (Butler, Chapman, Froman, \& Beck, 2006; Cuijpers, Berking, Andersson, Quigley, Kleiboer, \& Dobson, 2013; Hofman, Asnaani, Vonk, Sawyer, \& Fang, 2012; Hofman \& Smits, 2008; Linde, Sigtermna, Kriston, Rücker, Meissner, \& Schneider, 2015). However, there is still a number of people who either drop out of therapy (Fernandez, Salem, Swift, \& Ramtahal, 2015; Hans \& Hiller, 2013), complete therapy without complete remission of symptoms (Casacalenda, Perry, \& Looper, 2002; Springer, Levy, \& Tolin, 2018; Stein \& Clarske, 2017), relapse following treatment (Hofman \& Smits, 2008; Segal, Williams, \& Teasdale, 2002) or don't have adequate access to therapy at the first place (Kohn, Saxena, Levav, \& Saraceno, 2004).

Traditional psychological therapies focus mostly on the reduction of psychopathology rather than on the development of well-being, which in turn means that even after successful treatment of depression or anxiety people's well-being may still be languishing (Huppert \& Whittington, 2003; Lames, Westerhof, Glas, \& Bohlmeijer, 2015; Westerhof \& Keyes, 2010). Disorder-specific models for depression and anxiety disorders mostly rely on explaining the links between thoughts, behaviours, and emotions and enable the person to identify more helpful cognitive and behavioural responses aiming to reduce the negative emotions and physiological symptoms caused by depression and anxiety. Therapy often ends before the person has learned ways to improve their well-being and develop positive aspects of themselves. The Positive Psychology movement was developed in order to address this issue and sheds lights on ways people can enrich their lives and develop their strengths.

The foundation of Positive Psychology in 1998 gave the momentum and increased interest in the development of empirically validated Positive Psychology Interventions (PPIs). PPIs are defined as therapeutic methods or intentional activities aiming to develop positive thoughts, emotions, and behaviours (Sin \& Luybomirsky, 2009). Initial results show that the application of PPIs result in the improvement of well-being, and the reduction of depression and anxiety (Bolier, Haverman, Westerhof, Riper, Smit, \& Bohlmeijer, 2013; Sin \& Luybomirsky, 2009). Specifically, the meta-analysis of Sin and Lyubomirsky (2009), which included 51 PPIs, showed effect sizes ranging from small $(-0.28)$ to large $(0.81)$ on the measures of depression. Later in another meta-analysis, Bolier et al. (2013) adopted stricter inclusion criteria and included 39 studies with over 6.139 participants, finding a small effect size on the mean difference between the intervention and control group. The implications of those findings are that PPIs could enrich the effectiveness of established psychotherapeutic treatments of depression and anxiety.

Most evidence regarding the effectiveness of PPIs comes from studies with non-clinical samples (Bolier et al., 2013; Sin \& Lyubomirsky, 2009), but there are some initial studies exploring the effectiveness of PPIs in clinical populations (Chakhssi, Kraiss, Sommers-Spijkerman, \& Bohlmeijer, 2018). Studies to date indicate the effectiveness of PPIs when dealing with depression (Carr \& Finne- 
gan, 2015; Chaves, Lopez-Gomez, Hervas, \& Vazquez, 2017; Lopez-Gomez, Chaves, Hervas, \& Vazquez, 2017), depression comorbid with long-term conditions (Cohn, Pietrucha, Saslow, Hult, \& Moskowitz, 2014; D’raven, Moliver, \& Thompson, 2015), psychosis (Riches, Schrank, Rashid, \& Slade, 2016; Schrank, Brownell, Jakaite, Larkin, Pesola, Riches et al., 2016), schizophrenia (Meyer, Johnson, Parks, Iwanski, \& Penn, 2012), suicidality (Huffman, DuBois, Healy, Boehm, Kashdan, Celano et al., 2014), addiction problems (Krentzman, 2013) and with sub-clinical mental health difficulties such as depressive symptoms (Guo, Zhang, Plummer, Lam, Cross, \& Zhang, 2017).

The effectiveness of the PPIs has been tested in many cultures beyond English-speaking populations. For example, there are PPIs studies in Norway (Drozd, Mork, Nielsen, Raeder, \& Bjørkli, 2014), Switzerland (Gander, Proyer, Ruch, \& Wyss, 2013), Turkey (Koydemir \& Sun-Selisik, 2015), Israel (Gelfin, Zohar, \& Lev-Ari, 2018) Iran (Dowlatabadi et al., 2016), Japan (Otake, Shimai, TanakaMatsumi, Otsui, \& Fredrickson, 2006), China (Lü, Wang, \& Liu, 2013), Korea (Im, 2016), Taiwan (Wu \& Koo, 2016) or Suriname (Hendricks, 2017). To date there have been some initial research in Greece by Symeonidou, Moraitou, Pezirkianidis, \& Stalikas (2018) and Dimitropoulou \& Leontopoulou (2017).

Albeit the initial evidence for the effectiveness of PPIs, more studies are needed in order to further support their effectiveness in the treatment of symptoms of depression and anxiety (Hone, Jarden, \& Schofield, 2015; Walsh, Cassidy, \& Priebe, 2017). It has been established that therapies focusing on developing aspects of the well-being equips people to manage in life any early symptoms signaling mental health problems (Grant, Guille, \& Sen, 2013; Schotanus-Dijkstra, Ten Have, Lamers, deGraaf, \& Bohlmeijer, 2016; Slade, 2010). Higher levels of well-being is not only a protective factor for the prevention of mental health difficulties (Cohn, Fredrickson, Brown, Mikels, \& Conway, 2009; Grant, Munk, \& Hennig, 2018; Wood \& Joseph, 2010; Wood \& Tarrier, 2010), but it is also a basic component of any therapy as it leads to fewer relapses (Zimmerman, McGlinchey, Posternak, Friedman, Attiullah, \& Boerescu, 2006). The need of more research to focus on the development of the well-being has also been highlighted by the European agenda on public mental health (Forsman et al., 2015). Lastly, considering the stigma attached to mental health, we believe that it is more likely for people to opt in for treatments aiming to develop their well-being than those who focus on fixing part of their difficulties. Briefly, we argue that PPIs could provide an alternative to the management and prevention of common mental health disorders and this is what we want to test with this study.

The aim of this study is to develop a structured psycho-educational intervention programme consisting of empirically validated PPIs and examine its effectiveness on people with symptoms of depression, anxiety or stress in Greece. Our hypothesis is that the programme will lead to lower levels of depression, anxiety, stress, and negative emotions and to higher levels of life satisfaction and 
experience of positive emotions. The research questions of this study are:

1) Does a PPI psycho-educational intervention programme lead to a decrease in levels of depression, anxiety, stress, and negative emotions?

2) Does a PPI psycho-educational intervention programme lead to an increase in levels of life satisfaction and experience of positive emotions?

\section{Method}

\subsection{Study Design}

The first step of this study was the development of the material to be used in the structured psycho-education intervention programme, named "Be your Best You”. In order to accomplish this aim, a literature review of empirically validated PPIs was carried out (Kotsoni, Yotsidi, \& Karakasidou, in press) and then semi-structured interviews were conducted with Psychologists, trained in different Psychotherapeutic methods) specialised in Positive Psychology.

The aim of the literature review was to identify PPIs that have been empirically validated and were used with people with symptoms of depression, anxiety or stress. The most commonly used and empirically validated interventions were the 1) three good things (Seligman, Steen, Park, \& Peterson, 2005), 2) using your strengths in a new way (Seligman et al., 2005; Wood, Linley, Maltby, Kashda, \& Hurling, 2011), 3) goal setting (MacLeod, Coates, \& Hetherton, 2008; Sheldon, Kasser, Smith, \& Share, 2002), 4) savoring techniques (Smith, Harrison, Kurtz, \& Bryant, 2014), 5) positive relationships (Coan, Schaefer, \& Davidson, 2006; Reyes-García, Godoy, Vadez, Ruiz-Mallen, Huanca, Leonard et al., 2009), 6) best possible self (King, 2001; Layous, Nelson, \& Lyubomisky, 2013), 7) capitalising positive news (Gable \& Reis, 2010; Demir, Haynes, \& Potts, 2017; Demir, Tyra, \& Özen-Çıplak, 2018), and 8) random acts of kindness (Lyubomirsky, Sheldon, \& Schkade, 2005; Otake et al., 2006) (See Table 1).

After the selection of the positive psychology interventions to be included in the Be Your Best You, the presentation order had to be decided. Also, as not previously used in the Greek population, cultural factors had to be taken into

Table 1. Empirically validated PPIs.

\begin{tabular}{|c|c|}
\hline 3 good things & List three things that went well today and the reason why. \\
\hline $\begin{array}{l}\text { Using your strengths } \\
\text { in a new way }\end{array}$ & $\begin{array}{l}\text { Complete the VIA Character Strengths Survey to identify your strengths } \\
\text { and use your top strengths in a new way each day of the week. }\end{array}$ \\
\hline Goal setting & Set SMART goals. \\
\hline Savoring techniques & In-vivo savouring exercises \& introduction to savouring techniques. \\
\hline Positive relationships & Improve relationships with significant others. \\
\hline Best possible self & $\begin{array}{l}\text { Imagine your best possible future self and consider how you can } \\
\text { actualize this future. }\end{array}$ \\
\hline Capitalising positive news & Active /Constructive Responding to positive news. \\
\hline Random acts of kindness & Perform three acts of kindness within a single day. \\
\hline
\end{tabular}


consideration in the sequence. The researcher carried out five semi-structured interviews with Psychologists trained in Positive Psychology, who use PPIs in their clinical practice for depression, anxiety or stress. The main objective of the interviews was to determine the factors leading to the inclusion of PPIs in a psychotherapeutic process and how they are presented. Also, it was explored whether therapists come across any obstacles and how they tackle them, as well as whether the PPIs may contribute to the therapeutic outcome. The analysis of the interviews determined the sequence and final structure of the programme material.

\subsection{Participants}

First-year undergraduate Psychology students $(\mathrm{N}=94)$ completed the battery of the questionnaires. Those with severe or very severe symptoms of depression, anxiety or stress as measured by DASS $(\mathrm{N}=26)$ were randomly assigned to the intervention (12) and the control groups (14). Participants were not excluded or selected based on the existence of a mental illness diagnosis. Twelve participants were invited to participate in the intervention group and 8 completed the $\mathrm{Be}$ Your Best You programme. Eleven were women and there was one male with age ranging from 18 to $21(\mathrm{M}=18.50 \mathrm{SD}=1.00)$. Eleven out of fourteen women of the control group completed the measures both times. Their ages ranged from 18 to $34(\mathrm{M}=19.21 \mathrm{SD}=4.26)$. All participants spoke fluently Greek and were representative of the university population (See Table 2 ).

\subsection{Measures}

\section{Depression Anxiety Stress Scale (DASS)}

Participants completed the 21-item DASS (Lovibond \& Lovibond, 1995; Lyrakos, Arvaniti, Smyrnioti, \& Kostopanagiotou, 2011), which assesses symptoms of depression, anxiety, and stress. They were asked to choose the frequency of symptoms of depression (e.g. "I felt down-hearted and blue"), anxiety (e.g. "I felt I was close to panic), and stress (e.g. "I found it hard to wind down") over the past week. The participants choose their response from a 4-point scale ranging from 0 ("Did not apply to me at all") to 3 ("Applied to me very much or most of the time") for each question. A score for each of the three components of the questionnaire was calculated, by multiplying the mean of each dimension by two. Higher scores indicate higher levels of depression, anxiety and stress respectively. The Greek version of DASS was used. In this study's sample, the

Table 2. Group demographics.

\begin{tabular}{ccc}
\hline & Intervention Group $(\mathrm{N}=12)$ & Control Group $(\mathrm{N}=14)$ \\
\hline Sex N (\%) & $11(92 \%)$ & $13(100 \%)$ \\
Women & $1(8 \%)$ & $0(0 \%)$ \\
Men & $18.50(1.00)$ & $19.21(4.26)$ \\
Age $\mathrm{M}(S D)$ &
\end{tabular}


internal consistency reliability was for the sub-scale of depression $\alpha=0.90$, for the sub-scale of anxiety $\alpha=0.74$, and for the sub-scale of stress $\alpha=0.83$.

\section{Positive and Negative Affect Scale (PANAS)}

The experience of positive and negative affect was measured by the PANAS (Daskalou \& Sigkollitou, 2012; Watson, Clark, \& Tellegen, 1988), a 20-item selfreport questionnaire. The questionnaire includes ten questions for the experience of positive affect (e.g. "enthusiastic, active, proud") and ten for the experience of negative affect (e.g. "afraid, distressed, guilty"). Each item is measured on a Likert scale ranging from 1 ("very slightly or not at all") to 5 ("extremely"). A separate score of positive and negative affect is calculated with higher scores indicating greater levels of positive and negative emotions accordingly. The Greek version, which developed by Daskalou \& Sigkollitou (2012) was used. In this study, the Cronbach's $\alpha$ for the positive affect was $\alpha=0.83$ and the negative affect was $\alpha=0.86$.

\section{Satisfaction with Life Scale (SWLS)}

Satisfaction with life was measured with the SWLS (Diener, Emmons, Larsen, \& Griffin, 1985), which is a 7-item self-report questionnaire of global life satisfaction. The participants gave their answers on a 7-points Likert-scale ranging from 1 ("strongly disagree") to 7 ("strongly agree"). Examples of questions were: If I could live my life over, I would change almost nothing". The questionnaire has been standardised in the Greek population by Stalikas \& Lakioti in 2012 and the Cronbach's a for this study was a $=0.78$.

\subsection{Procedure}

The participants in this study were first-year Psychology students. Participants completed the screening questionnaires and were verbally and written presented with the details of the study during a lecture. They signed an informed consent in order to participate in the study, which gave details about the confidentiality of their data and their right to withdraw from the study at any time. For the analysis of the questionnaires, each participant was allocated a unique code in order to secure their privacy and anonymity. After the completion of the screening process, an invitation to the Be Your Best You was sent via e-mail to those reported severe or very severe symptoms of depression, anxiety or stress. Those who agreed to participate were randomly allocated in the experimental and control groups. Measures were taken at two points: before the beginning of the programme (T1) and at the end of the programme (T2).

The present study was conducted in accordance with the ethical research guidelines of the Greek Psychological Society. After the completion of the study, participants in the control group were offered the opportunity to attend the Be Your Best You.

Each session lasted 90 minutes and included psycho-education information, experiential exercises, paired exercises and homework. In Table 3 the material covering in each session and the homework allocated is presented. In the first 
Table 3. Session by session content of the be your best you.

\begin{tabular}{|c|c|c|c|c|c|c|}
\hline & $\begin{array}{l}\text { Session } 1 \\
\text { The Pilot }\end{array}$ & $\begin{array}{c}\text { Session } 2 \\
\text { Character Strenghts }\end{array}$ & $\begin{array}{l}\text { Session } 3 \\
\text { Savoring }\end{array}$ & $\begin{array}{c}\text { Session } 4 \\
\text { Meaning of life }\end{array}$ & $\begin{array}{c}\text { Session } 5 \\
\text { Positive relationships }\end{array}$ & $\begin{array}{l}\text { Session } 6 \\
\text { Final }\end{array}$ \\
\hline In the session & $\begin{array}{l}\text { Warm-up exercise } \\
\text { Happiness theories } \\
\text { Programme overview }\end{array}$ & $\begin{array}{l}\text { Character Strengths } \\
\text { Goal Setting }\end{array}$ & $\begin{array}{l}\text { Positive Emotions } \\
\text { Broaden-and- } \\
\text { build-theory } \\
\text { Savoring exercises }\end{array}$ & $\begin{array}{l}\text { Meaning of life } \\
\text { Best possible self } \\
\quad \text { exercise }\end{array}$ & $\begin{array}{c}\text { Characteristics of } \\
\text { positive relationships } \\
\text { Capitalising positive } \\
\text { news } \\
\text { Gratitude Letter }\end{array}$ & $\begin{array}{c}\text { Review material } \\
\text { Relapse-prevention }\end{array}$ \\
\hline Homework & $\begin{array}{l}3 \text { good things } \\
\text { Complete VIA } \\
\text { Questionnaire }\end{array}$ & $\begin{array}{l}\text { Use your character } \\
\text { strength in a new } \\
\text { way each day } \\
\text { Goal setting }\end{array}$ & $\begin{array}{l}\text { Identify activities that } \\
\text { increase happiness } \\
\text { Practice savoring }\end{array}$ & $\begin{array}{l}\text { Set goals based } \\
\text { on your best } \\
\text { possible self }\end{array}$ & $\begin{array}{c}\text { Communicate } \\
\text { positively } \\
\text { Share a positive } \\
\text { exercise with a friend }\end{array}$ & N/A \\
\hline
\end{tabular}

session, the focus was on building a safe group environment. During the session, we discussed happiness based on recent findings on the field. The participants were asked to record " 3 good things" at the end of each day for the following week, as well as to complete the VIA questionnaire. Session 2 focused on finding ways to strengthen the character strengths of each participant. Moreover, the principles of goal setting were presented, and each participant set three therapy goals. In Session 3, the positive emotions, the broaden-and-build theory, and savoring techniques were discussed. Participants were asked to consider what activities increase the experience of positive emotions in their lives and practice new ways to savor past, present or future experiences. During the coming week, they were asked to practice savoring daily. In the following week, we discussed the meaning of life and participants completed the "My best-self exercise". The homework for this week was for each participant to review their therapy goals in light of the new exercise. Session 5 focused on relationships, specifically, on positive relationships, on expressing gratitude and on capitalizing on positive news. As homework, the participants reflected on how they can be more active and positive in their social interactions and asked to share one of the exercises covered with a friend or a family member. In the final session, we recapped what was covered in the programme and participants were encouraged to build a relapse-prevention plan.

After each session, participants completed written feedback forms, which were later utilized for the revision of the material and the exercises. Two Ph.D. students delivered the intervention, a Psychologist and a Licensed CBT Psychotherapist and a Registered Nurse.

\section{Results}

Statistical analyses were conducted using the R Project for Statistical Computing and the Statistical Analysis Statistics Version 25.

The data were tested for normality and all apart from the positive emotions for the control group followed a normal distribution, which indicated that parametric tests could be run. No significant differences were detected between the control and the experimental group in any of the demographic characteristics or 
measures prior to the beginning of the intervention. To answer the research questions a series of one-tailed paired samples t-tests were employed to compare pre- and post-measures in study outcomes for the experimental and control group.

For the experimental group, statistically significant decrease was observed for depression $(\mathrm{t}=3.0119, p=0.010)$, anxiety $(\mathrm{t}=3.1646, p=0.080)$, stress $(\mathrm{t}=$ $2.5364, p=0.019)$ and negative emotions $(\mathrm{t}=1.5055, p=0.088)$ when comparing the scores before and after the programme. The prices of the depression, anxiety, stress and negative emotions dropped significantly in the post-measure. The second hypothesis was not supported as the expected statistically significant increase positive emotions $(\mathrm{t}=-1.355, p=0.891)$ and satisfaction with life $(\mathrm{t}=$ $0.58, p=0.478$ ) was not observed. The positive emotions remain almost stable and the increase in satisfaction with life was not statistically significant (Table 4).

We also calculated the effect sizes by using means, standard deviations, and sample sizes in order to measure the magnitude of the difference in our variables before and after the intervention. Due to the small sample size, we chose to calculate the Hedges' corrected g (Cuijpers, 2016), which is more accurate when there is a sample of less than 20. The effect size indicates the magnitude of the difference between the two scores. Effect size below 0.2 can be considered as small, effect sizes of 0.5 as a medium, and effect sizes of 0.8 as large (Cohen, 1988). In Table 4 we can see the effect sizes for the changes in the experimental group for each measure before and after the intervention. The Hedge's g effect sizes for depression, anxiety, stress, and negative emotions were large, further supporting our first research question. For satisfaction with life, there was a small effect size and no effect size was observed for positive emotions.

The same statistical analyses were carried out for the control group. According to one-tailed t-tests, no statistically significant difference was found when comparing the pre- and post-intervention scores in terms of depression $(\mathrm{t}=$ -1.0569, $p=0.852)$, anxiety $(\mathrm{t}=0.31784, p=0.376)$, stress $(\mathrm{t}=-0.444, p=$ $0.671)$, negative emotions $(\mathrm{t}=0.5531, p=0.291)$ and satisfaction with life $(\mathrm{t}=$ $-1.355, p=0.891)$. Although negligible, the scores for depression, stress, and negative emotions had an increase six weeks after the initial measure. Also, there

Table 4. Pre-test and post-test results for the experimental group.

\begin{tabular}{ccccc}
\hline & $\begin{array}{c}\text { Pre-programme (T1) } \\
\text { M (SD) }\end{array}$ & $\begin{array}{c}\text { Post-programme (T2) } \\
\text { M (SD) }\end{array}$ & t & Hedge's g \\
\hline Depression & $21.00(8.816)$ & $12.50(11.353)$ & $3.0119^{*}$ & 0.791 \\
Anxiety & $17.50(7.540)$ & $7.25(4.268)$ & $3.1646^{*}$ & 1.582 \\
Stress & $22.50(7.690)$ & $12.75(6.319)$ & $2.5364^{*}$ & 1.310 \\
Positive Emotions & $28.50(8.053)$ & $28.38(9.226)$ & -1.355 & 0.0136 \\
Negative Emotions & $30.50(9.243)$ & $24.38(5.423)$ & 1.5055 & 0.764 \\
Satisfaction with Life & $22.88(3.563)$ & $24.88(5.330)$ & 1.355 & -0.417 \\
\hline${ }^{*} p<0.05$. & & & &
\end{tabular}


was a decrease in satisfaction with life, although not statistically significant. For the variable of positive emotions, which was not normally distributed, the non-parametric Wilcoxon test was run $(\mathrm{V}=786, p=0.250)$. Also, all the effect sizes were calculated, and it was shown that their effect was negligible apart from the satisfaction with life that indicates a small effect size (Table 5 \& Table 6).

To summarise the results, the first hypothesis was supported and the participants in the intervention group moved from the severe range of symptoms for depression anxiety and depression to the mild one, also their levels of stress started on moderate and ended in normal. No such benefits were observed in the control group. The implications of these findings will be discussed in the next section.

\section{Conclusion}

The primary goal for this study was to design a structured psycho-educational intervention programme and to explore its effectiveness for the Greek population with depression, anxiety or stress. The findings of this study provide preliminary evidence for the effectiveness of the Be Your Best You programme. People who participated in the intervention reported significantly decreased levels of depression, anxiety, stress, and negative emotions, as well as an increase in satisfaction with life after the completion of the programme. Moreover, as measured by the effect size the impact ranged from small (satisfaction with life) to large (depression, anxiety, stress, and negative emotions). At the same time, for the participants in the control group, no changes were observed in their levels of depression, anxiety, stress, positive or negative emotions before and after the 6-weeks period.

In line with previous studies, which support the effectiveness of PPIs in the reduction of depression, anxiety or stress (e.g. Hanson, 2019; Pintado, Castillo, \&

Table 5. Pre-test and post-test results for the control group.

\begin{tabular}{ccccc}
\hline & $\begin{array}{c}\text { Pre-programme (T1) } \\
\text { M (SD) }\end{array}$ & $\begin{array}{c}\text { Post-programme (T2) } \\
\text { M (SD) }\end{array}$ & t & Hedge's g \\
\hline Depression & $24.73(9.603)$ & $25.27(8.776)$ & -1.0569 & -0.114 \\
Anxiety & $14.00(9.077)$ & $12.73(7.226)$ & 0.31784 & 0.0474 \\
Stress & $20.18(9.141)$ & $23.82(8.554)$ & -0.444 & -0.060 \\
Negative Emotions & $24.36(8.559)$ & $28.27(7.471)$ & 0.5531 & 0.084 \\
Satisfaction with Life & $20.09(5.504)$ & $18.00(4.359)$ & -1.355 & 0.193 \\
\hline
\end{tabular}

${ }^{*} p \leq 0.05$.

Table 6. Pre-test and post-test results for positive emotions (control group).

\begin{tabular}{lcccc}
\hline & $\begin{array}{c}\text { Pre-programme (T1) } \\
\text { M (SD) }\end{array}$ & $\begin{array}{c}\text { Post-programme (T2) } \\
\text { M (SD) }\end{array}$ & V & Hedge's g \\
\hline Positive Emotions & $26.27(9.318)$ & $28.09(8.769)$ & 786 & 0.054 \\
\hline${ }^{*} p \leq 0.05$. & & & &
\end{tabular}


Penagos-Corzo, 2018), the results of this study indicate that PPIs could take a more central role in the management of common mental health disorders.

The only hypothesis of the study that has not been confirmed was that the positive emotions were not increased as predicted among the participants to the programme. A possible explanation for this finding may have been that there was not enough time for the participants to process both cognitive and emotional changes. Often, people in therapy report that they can logically see the difference, but they “don't feel it" (Lorenzo-Luaces, German, \& DeRubeis, 2015). Similarly, in this study, we observe cognitive change through life satisfaction as measured by the effect size, but participants may have required a longer time in order to experience the emotional benefits. A follow-up measurement could have been beneficial in exploring this.

\section{Clinical \& Research Implications}

This is the first known multi-component Positive Psychology intervention that has been tested on the Greek population among adults. Those results do not only set the basis for further research to be conducted in Greece for the replication of those findings but also have some significant clinical implications.

In this study, the programme was delivered to Psychology students. This population is often highly motivated and engages well with the process. For the findings' generalizability, more studies including a more diverse population in terms of sex, age, profession, and marital status are needed. Also, the nature of this programme's material makes it easily transferred to other populations and or settings. Future studies could be delivered to groups who are at risk of developing mental health difficulties, such, people with long-term conditions, refugees, people working in an environment with increased stressed e.g. police officers or carers of people with learning or physical disabilities. Future designs would also benefit from the inclusion of follow-up measures in order to strengthen the results and explore the lasting effect of the changes observed after the completion of the programme.

Thanks to the significant reduction in mental health symptoms and the improvement in the well-being observed in this study, psychotherapists could consider the whole programme or adopt part of it for their clinical practice. Psychotherapists could use the positive interventions for group or individual interventions for people presenting to therapy for symptoms of anxiety, depression or stress. Other studies have also shown that positive psychology interventions could compliment traditional psychotherapy (Wong et al., 2018). As well as in individual and group therapies, the material of this programme could be adjusted and utilised in online or self-help guided forms of therapy (Gander, Proyer, \& Ruch, 2016; Woodworth, O’Brien-Malone, Diamond, \& Schüz, 2018).

A benefit for this intervention programme is that it is transdiagnostic, which provides flexibility to the recruitment criteria of future studies. As clinical and non-clinical settings are usually quite diverse, this programme would require 
fewer resources to run. Future studies could also explore whether people presenting initially with anxiety or depression benefit differently from this intervention. For example, components of this study such as identify activities that increase happiness may be more beneficial for depressed people and act as a way to increase their levels of daily activities, which is an adjustment of a widely-used CBT intervention for depression (see behavioural activation in Dimidjian, Martell, Herman-Dunn, \& Hubley, 2014).

Although in this programme the sessions run for 90 minutes, if more people participate (more than 10), it may be beneficial to consider increasing the time, so it enables everyone to actively participate in each meeting. In this study, none of the programme facilitators had any previous experiences in delivering a Positive Psychology intervention but achieved to do so with the supervision of experienced clinicians. A benefit of this intervention programme is that it could be easily taught to mental health professionals and be delivered under supervision of an experienced psychotherapist, which addresses the global shortage of experienced therapists and appropriately organised services (Barbato, Vallarino, Rapisarda, Lora, Miguel, \& de Almeida, 2016).

A great benefit of Positive Psychology and this programme is that it addresses variables that are more likely to engage people. Nowadays, most people are interested in exploring ways to improve their well-being. This in combination with the fact that people are often unaware that the source of their difficulties is linked with mental health difficulties could make this programme a good prevention intervention. Also, people who are not assessing mental health services due to the stigma attached to them are likely to find this intervention more engaging (Mojtabai, Olfson, \& Mechanic, 2002). Finally, with adjustments, the programme can be used as a mental health prevention tool for the general population and benefit other age groups such as adolescents and elderly people.

\section{Conflicts of Interest}

The authors declare no conflicts of interest regarding the publication of this paper.

\section{References}

Barbato, A., Vallarino, M., Rapisarda, F., Lora, A., Miguel, J., \& de Almeida, J. (2016). Access to Mental Health Care in Europe: Consensus Paper. Brussels: European Commission.

Bolier, L., Haverman, M., Westerhof, G. J., Riper, H., Smit, F., \& Bohlmeijer, E. (2013). Positive Psychology Interventions: A Meta-Analysis of Randomised Controlled Trials. BMC Public Health, 13, Article No. 119. https://doi.org/10.1186/1471-2458-13-119

Butler, A., Chapman, J. E., Froman, E. M., \& Beck, A. T. (2006). The Empirical Statues of Cognitive-Behavioral Therapy: A Review of Meta-Analyses. Clinical Psychology Review, 26, 17-31. https://doi.org/10.1016/j.cpr.2005.07.003

Carr, A., \& Finnegan, L. (2015). The Say "Yes" to Life (SYTL) Program: A Positive Psychology Group Intervention for Depression. Journal of Contemporary Psychotherapy, 45, 109-118. https://doi.org/10.1007/s10879-014-9269-9 
Casacalenda, N., Perry, J. C., \& Looper, K. (2002). Remission in Major Depressive Disorder: A Comparison of Pharmacotherapy, Psychotherapy, and Control Conditions. The American Journal of Psychiatry, 159, 1354-1360. https://doi.org/10.1176/appi.ajp.159.8.1354

Chakhssi, F., Kraiss, J. T., Sommers-Spijkerman, M., \& Bohlmeijer, E. T. (2018). The Effect of Positive Psychology Interventions on Well-Being and Distress in Clinical Samples with Psychiatric or Somatic Disorders: A Systematic Review and Meta-Analysis. BMC Psychiatry, 18, Article No. 211. https://doi.org/10.1186/s12888-018-1739-2

Chaves, C., Lopez-Gomez, I., Hervas, G., \& Vazquez, C. (2017). A Comparative Study on the Efficacy of a Positive Psychology Intervention and a Cognitive Behavioral Therapy for Clinical Depression. Cognitive Therapy and Research, 41, 417-433. https://doi.org/10.1007/s10608-016-9778-9

Coan, J. A., Schaefer, H. S., \& Davidson, R. J. (2006). Lending a Hand: Social Regulation of the Neural Response to Threat. Psychological Science, 17, 1032-1040.

https://doi.org/10.1111/j.1467-9280.2006.01832.x

Cohn, M. A., Fredrickson, B. L., Brown, S. L., Mikels, J. A., \& Conway, A. M. (2009). Happiness Unpacked: Positive Emotions Increase Life Satisfaction by Building Resilience. Emotion, 9, 361-368. https://doi.org/10.1037/a0015952

Cohn, M. A., Pietrucha, M. E., Saslow, L. R., Hult, J. R., \& Moskowitz, J. T. (2014). An Online Positive Affect Skills Intervention Reduces Depression in Adults with Type 2 Diabetes. The Journal of Positive Psychology, 9, 523-534. https://doi.org/10.1080/17439760.2014.920410

Cuijpers, P. (2016). Meta-Analyses in Mental Health Research: A Practical Guide. Amsterdam, The Netherlands: Vrije Universiteit Amsterdam.

Cuijpers, P., Berking, M., Andersson, G., Quigley, L., Kleiboer, A., \& Dobson, K. S. (2013). A Meta-Analysis of Cognitive-Behavioural Therapy for Adult Depression, Alone and in Comparison with Other Treatments. The Canadian Journal of Psychiatry, 58, 376-385. https://doi.org/10.1177/070674371305800702

D’raven, L. T. L., Moliver, N., \& Thompson, D. (2015). Happiness Intervention Decreases Pain and Depression, Boosts Happiness among Primary Care Patients. Primary Health Care Research \& Development, 16, 114-126. https://doi.org/10.1017/S146342361300056X

Daskalou, \& Sigkollitou (2012). Positive and Negative Affect Scale (PANAS). In A. Stalikas, S. Triliva, \& P. Roussi (Eds.), Psychometric Instruments in Greece (2nd ed., p. 526). Athens: Pedio.

Demir, M., Haynes, A., \& Potts, S. K. (2017). My Friends Are My Estate: Friendship Experiences Mediate the Relationship between Perceived Responses to Capitalization Attempts and Happiness. Journal of Happiness Studies, 18, 1161-1190.

https://doi.org/10.1007/s10902-016-9762-9

Demir, M., Tyra, A., \& Özen-Çıplak, A. (2018). Be There for Me and I Will Be There for You: Friendship Maintenance Mediates the Relationship between Capitalization and Happiness. Journal of Happiness Studies, 21, 449-469.

https://doi.org/10.1007/s10902-017-9957-8

Diener, E. D., Emmons, R. A., Larsen, R. J., \& Griffin, S. (1985). The Satisfaction with Life Scale. Journal of Personality Assessment, 49, 71-75. https://doi.org/10.1207/s15327752jpa4901_13

Dimidjian, S., Martell, C. R., Herman-Dunn, R., \& Hubley, S. (2014). Behavioral Activation for Depression. In D. H Barlow (Eds.), Clinical Handbook of Psychological Disorders (4th ed., pp. 353-393). New York: The Guildford Press. 
Dimitropoulou, C., \& Leontopoulou, S. (2017). A Positive Psychological Intervention to Promote Well-Being in a Multicultural School Setting in Greece. The European Journal of Counselling Psychology, 6, 113-137. https://doi.org/10.5964/ejcop.v6i1.141

Dowlatabadi, M. M., Ahmadi, S. M., Sorbi, M. H., Beiki, O., Razavi, T. K., \& Bidaki, R. (2016). The Effectiveness of Group Positive Psychotherapy on Depression and Happiness in Breast Cancer Patients: A Randomized Controlled Trial. Electronic Physician, 8, 2175-2180. https://doi.org/10.19082/2175

Drozd, F., Mork, L., Nielsen, B., Raeder, S., \& Bjørkli, C. A. (2014). Better Days-A Randomized Controlled Trial of an Internet-Based Positive Psychology Intervention. The Journal of Positive Psychology, 9, 377-388. https://doi.org/10.1080/17439760.2014.910822

Fernandez, E., Salem, D., Swift, J. K., \& Ramtahal, N. (2015). Meta-Analysis of Dropout from Cognitive Behavioral Therapy: Magnitude, Timing, and Moderators. Journal of Consulting and Clinical Psychology, 83, 1108-1122. https://doi.org/10.1037/ccp0000044

Forsman, A. K., Wahlbeck, K., Aarø, L. E., Alonso, J., Barry, M. M., Brunn, M. et al. (2015). Research Priorities for Public Mental Health in Europe: Recommendations of the ROAMER Project. The European Journal of Public Health, 25, 249-254. https://doi.org/10.1093/eurpub/cku232

Gable, S. L., \& Reis, H. T. (2010). Good News! Capitalizing on Positive Events in an Interpersonal Context. In Advances in Experimental Social Psychology (Vol. 42, pp. 195-257). Cambridge, MA: Academic Press. https://doi.org/10.1016/S0065-2601(10)42004-3

Gander, F., Proyer, R. T., \& Ruch, W. (2016). Positive Psychology Interventions Addressing Pleasure, Engagement, Meaning, Positive Relationships, and Accomplishment Increase Well-Being and Ameliorate Depressive Symptoms: A Randomized, PlaceboControlled Online Study. Frontiers in Psychology, 7, 686.

https://doi.org/10.3389/fpsyg.2016.00686

Gander, F., Proyer, R. T., Ruch, W., \& Wyss, T. (2013). Strength-Based Positive Interventions: Further Evidence for Their Potential in Enhancing Well-Being and Alleviating Depression. Journal of Happiness Studies, 14, 1241-1259.

https://doi.org/10.1007/s10902-012-9380-0

Gelfin, M., Zohar, A. H., \& Lev-Ari, L. (2018). Personality Change and Therapeutic Gain: Randomized Controlled Trial of a Positive Psychology Intervention. International Journal of Psychology \& Psychological Therapy, 18, 193-205.

Grant, F., Guille, C., \& Sen, S. (2013). Well-Being and the Risk of Depression under Stress. PLoS ONE, 8, e67395. https://doi.org/10.1371/journal.pone.0067395

Grant, P., Munk, A. J. L., \& Hennig, J. (2018). A Positive-Psychological Intervention Reduces Acute Psychosis-Proneness. Schizophrenia Research, 199, 414-419.

https://doi.org/10.1016/j.schres.2018.04.007

Guo, Y. F., Zhang, X., Plummer, V., Lam, L., Cross, W., \& Zhang, J. P. (2017). Positive Psychotherapy for Depression and Self-Efficacy in Undergraduate Nursing Students: A Randomized, Controlled Trial. International Journal of Mental Health Nursing, 26, 375-383. https://doi.org/10.1111/inm.12255

Hans, E., \& Hiller, W. (2013). Effectiveness of and Dropout from Outpatient Cognitive Behavioral Therapy for Adult Unipolar Depression: A Meta-Analysis of Nonrandomized Effectiveness Studies. Journal of Consulting and Clinical Psychology, 81, 75-88. https://doi.org/10.1037/a0031080

Hanson, K. (2019). Positive Psychology for Overcoming Symptoms of Depression: A Pilot Study Exploring the Efficacy of a Positive Psychology Self-Help Book versus a CBT 
Self-Help Book. Behavioural and Cognitive Psychotherapy, 47, 95-113. https://doi.org/10.1017/S1352465818000218

Hofman, S. G., \& Smits, J. A. (2008). Cognitive-Behavioral Therapy for Adult Anxiety Disorders: A Meta-Analysis of Randomized Placebo-Controlled Trials. The Journal of Clinical Psychiatry, 69, 621-632.

https://www.psychiatrist.com/jcp/article/Pages/2008/v69n04/v69n0415.aspx https://doi.org/10.4088/JCP.v69n0415

Hofman, S. G., Asnaani, A., Vonk, I. J. J., Sawyer, A. T., \& Fang, A. (2012). The Efficacy of Cognitive Behavioral Therapy: A Review of Meta-Analyses. Cognitive Therapy and Research, 36, 427-440. https://doi.org/10.1007/s10608-012-9476-1

Hone, L. C., Jarden, A., \& Schofield, G. M.(2015). An Evaluation of Positive Psychology Intervention Effectiveness Trials Using the Re-Aim Framework: A Practice-Friendly Review. Journal of Positive Psychology, 10, 303-322. https://doi.org/10.1080/17439760.2014.965267

Huffman, J. C., DuBois, C. M., Healy, B. C., Boehm, J. K., Kashdan, T. B., Celano, C. M. et al. (2014). Feasibility and Utility of Positive Psychology Exercises for Suicidal Inpatients. General Hospital Psychiatry, 36, 88-94. https://doi.org/10.1016/j.genhosppsych.2013.10.006

Huppert, F. A., \& Whittington, J. E. (2003). Evidence for the Independence of Positive and Negative Well-Being: Implications for Quality of Life Assessment. British Journal of Health Psychology, 8, 107-122. https://doi.org/10.1348/135910703762879246

Im, S. B., Cho, M.-K., Kim, S. Y., \& Heo, M. L. (2016). The Huddling Programme: Effects on Empowerment, Organisational Commitment and Ego-Resilience in Clinical NursesA Randomised Trial. Journal of Clinical Nursing, 25, 1377-1387. https://doi.org/10.1111/jocn.13228

King, L. A. (2001). The Health Benefits of Writing about Life Goals. Personality and Social Psychology Bulletin, 27, 798-807. https://doi.org/10.1177/0146167201277003

Kohn, R., Saxena, S., Levav, I., \& Saraceno, B. (2004). The Treatment Gap in Mental Health Care. Bulletin of the World Health Organization, 82, 858-866.

https://www.who.int/bulletin/volumes/82/11/en/858.pdf

Kotsoni, A., Yotsidi, V., \& Karakasidou, E. (in press). Evidence-Based Positive Psychology Intervention and Techniques. In V. Yotsidi, E. Karakasidou, \& A. Stalikas (Eds.), Positive Interventions and Techniques for Self-Growth and Well-Being. Athens: Topos.

Koydemir, S., \& Sun-Selisik, Z. (2015). Well-Being on Campus: Testing the Effectiveness of an Online Strengths-Based Intervention for First Year College Students. British Journal of Guidance \& Counselling, 44, 434-446. https://doi.org/10.1080/03069885.2015.1110562

Krentzman, A. R. (2013). Review of the Application of Positive Psychology to Substance Use, Addiction, and Recovery Research. Psychology of Addictive Behaviors, 27, 151165. https://doi.org/10.1037/a0029897

Layous, K., Nelson, S. K., \& Lyubomirsky, S. (2013). What Is the Optimal Way to Deliver a Positive Activity Intervention? The Case of Writing about One's Best Possible Selves. Journal of Happiness Studies, 14, 635-654. https://doi.org/10.1007/s10902-012-9346-2

Linde, K., Sigterman, K., Kriston, L., Rücker, G., Jamil, S., Meissner, K., \& Schneider, A. (2015). Effectiveness of Psychological Treatments for Depressive Disorders in Primary Care: Systematic Review and Meta-Analysis. The Annals of Family Medicine, 13, 56-68. https://doi.org/10.1370/afm.1719

Lopez-Gomez, I., Chaves, C., Hervas, G., \& Vazquez, C. (2017). Comparing the Acceptability of a Positive Psychology Intervention versus a Cognitive Behavioural Therapy 
for Clinical Depression. Clinical Psychology \& Psychotherapy, 24, 1029-1039.

https://doi.org/10.1002/cpp.2129

Lorenzo-Luaces, L., German, R. E., \& DeRubeis, R. J. (2015). It's Complicated: The Relation between Cognitive Change Procedures, Cognitive Change, and Symptom Change in Cognitive Therapy for Depression. Clinical Psychology Review, 41, 3-15. https://doi.org/10.1016/j.cpr.2014.12.003

Lovibond, P. F., \& Lovibond, S. H. (1995). The Structure of Negative Emotional States: Comparison of the Depression Anxiety Stress Scales (DASS) with the Beck Depression and Anxiety Inventories. Behaviour Research and Therapy, 33, 335-343. https://doi.org/10.1016/0005-7967(94)00075-U

Lü, W., Wang, Z., \& Liu, Y. (2013). A Pilot Study on Changes of Cardiac Vagal Tone in Individuals with Low Trait Positive Affect: The Effect of Positive Psychotherapy. International Journal of Psychophysiology, 88, 213-217.

https://doi.org/10.1016/j.ijpsycho.2013.04.012

Lyrakos, G. N., Arvaniti, C., Smyrnioti, M., \& Kostopanagiotou, G. (2011). P03-561Translation and Validation Study of the Depression Anxiety Stress Scale in the Greek General Population and in a Psychiatric Patient's Sample. European Psychiatry, 26, 1731. https://doi.org/10.1016/S0924-9338(11)73435-6

Lyubomirsky, S., Sheldon, K. M., \& Schkade, D. (2005). Pursuing Happiness: The Architecture of Sustainable Change. Review of General Psychology, 9, 111-131. https://doi.org/10.1037/1089-2680.9.2.111

MacLeod, A. K., Coates, E., \& Hetherton, J. (2008). Increasing Well-Being through Teaching Goal-Setting and Planning Skills: Results of a Brief Intervention. Journal of Happiness Studies, 9, 185-196. https://doi.org/10.1007/s10902-007-9057-2

Meyer, P. S., Johnson, D. P., Parks, A., Iwanski, C., \& Penn, D. L. (2012). Positive Living: A Pilot Study of Group Positive Psychotherapy for People with Schizophrenia. The Journal of Positive Psychology, 7, 239-248. https://doi.org/10.1080/17439760.2012.677467

Mojtabai, R., Olfson, M., \& Mechanic, D. (2002). Perceived Need and Help-Seeking in Adults with Mood, Anxiety, or Substance Use Disorders. Archives of General Psychiatry, 59, 77-84. https://doi.org/10.1001/archpsyc.59.1.77

Otake, K., Shimai, S., Tanaka-Matsumi, J., Otsui, K., \& Fredrickson, B. L. (2006). Happy People Become Happier through Kindness: A Counting Kindnesses Intervention. Journal of Happiness Studies, 7, 361-375. https://doi.org/10.1007/s10902-005-3650-Z

Pintado, S., Castillo, M., \& Penagos-Corzo, J. C. (2018). Comparing Cognitive-Behavior Therapy and Positive Psychology to Enhance Emotional Well-Being. Interamerican Journal of Psychology, 52, 171-182.

Reyes-García, V., Godoy, R. A., Vadez, V., Ruíz-Mallén, I., Huanca, T., Leonard, W. R. et al. (2009). The Pay-Offs to Sociability. Human Nature, 20, 431-446. https://doi.org/10.1007/s12110-009-9073-5

Riches, S., Schrank, B., Rashid, T., \& Slade, M. (2016). WELLFOCUS PPT: Modifying Positive Psychotherapy for Psychosis. Psychotherapy, 53, 68-77. https://doi.org/10.1037/pst0000013

Schotanus-Dijkstra, M., Ten Have, M., Lamers, S. M., de Graaf, R., \& Bohlmeijer, E. T. (2016). The Longitudinal Relationship between Flourishing Mental Health and Incident Mood, Anxiety and Substance Use Disorders. The European Journal of Public Health, 27, 563-568. https://doi.org/10.1093/eurpub/ckw202

Schrank, B., Brownell, T., Jakaite, Z., Larkin, C., Pesola, F., Riches, S. et al. (2016). Evaluation of a Positive Psychotherapy Group Intervention for People with Psychosis: Pilot 
Randomised Controlled Trial. Epidemiology and Psychiatric Sciences, 25, 235-246. https://doi.org/10.1017/S2045796015000141

Segal, Z. V., Williams, J. M. G., \& Teasdale, J. D. (2002). Mindfulness-Based Cognitive Therapy for Depression: A New Approach to Preventing Relapse. New York: The Guildford Press.

Seligman, M. E. P., Steen, T. A., Park, N., \& Peterson, C. (2005). Positive Psychology Progress: Empirical Validation of Interventions. American Psychologist, 60, 410-421. https://doi.org/10.1037/0003-066X.60.5.410

Sheldon, K. M., Kasser, T., Smith, K., \& Share, T. (2002). Personal Goals and Psychological Growth: Testing an Intervention to Enhance Goal Attainment and Personality Integration. Journal of Personality, 70, 5-31. https://doi.org/10.1111/1467-6494.00176

Sin, N. L., \& Lyubomirsky, S. (2009). Enhancing Well-Being and Alleviating Depressive Symptoms with Positive Psychology Interventions: A Practice-Friendly Meta-Analysis. Journal of Clinical Psychology, 65, 467-487. https://doi.org/10.1002/jclp.20593

Slade, M. (2010). Mental Illness and Well-Being: The Central Importance of Positive Psychology and Recovery Approaches. BMC Health Services Research, 10, Article No. 26. https://doi.org/10.1186/1472-6963-10-26

Smith, J. L., Harrison, P. R., Kurtz, J. L., \& Bryant, F. B. (2014). Nurturing the Capacity to Savor: Interventions to Enhance the Enjoyment of Positive Experiences. In A. C. Parks, \& S. M. Schueller (Eds.), The Wiley Blakcwell Handbook of Positive Psychological Interventions (pp. 42-65). West Sussex, UK: Wiley Blackwell. https://doi.org/10.1002/9781118315927.ch3

Springer, K. S., Levy, H. C., \& Tolin, D. F. (2018). Remission in CBT for Adult Anxiety Disorders: A Meta-Analysis. Clinical Psychology Review, 61, 1-8. https://doi.org/10.1016/j.cpr.2018.03.002

Stalikas, A., \& Lakioti, A. (2012). Satisfaction with Life Scale (SWLS). In A. Stalikas, S Triliva, \& P. Roussi (Eds.), Psychometric Instruments in Greece (2nd ed., p. 752). Athens: Pedio.

Stein, M. B., \& Clarske, M. G. (2017). Treating Anxiety in 2017: Optimizing Care to Improve Outcomes. Journal of the American Medical Association, 318, 235-236. https://doi.org/10.1001/jama.2017.6996

Symeonidou, D., Moraitou, D., Pezirkianidis, C., \& Stalikas, A. (2018). Promoting Subjective Wellbeing through a Kindness Intervention. Hellenic Journal of Psychology, 16, $1-21$.

Walsh, S., Cassidy, M., \& Priebe, S. (2017). The Application of Positive Psychotherapy in Mental Health Care: A Systematic Review. Journal of Clinical Psychology, 73, 638-651. https://doi.org/10.1002/jclp.22368

Watson, D., Clark, L. A., \& Tellegen, A. (1988). Development and Validation of Brief Measures of Positive and Negative Affect: The PANAS Scales. Journal of Personality and Social Psychology, 54, 1063-1070. https://doi.org/10.1037/0022-3514.54.6.1063

Westerhof, G. J., \& Keyes, C. L. (2010). Mental Illness and Mental Health: The Two Continua Model across the Lifespan. Journal of Adult Development, 17, 110-119. https://doi.org/10.1007/s10804-009-9082-y

Wong, Y. J., Owen, J., Gabana, N. T., Brown, J. W., McInnis, S., Toth, P., \& Gilman, L. (2018). Does Gratitude Writing Improve the Mental Health of Psychotherapy Clients? Evidence from a Randomized Controlled Trial. Psychotherapy Research, 28, 192-202. https://doi.org/10.1080/10503307.2016.1169332

Wood, A. M., \& Joseph, S. (2010). The Absence of Positive Psychological (Eudemonic) 
Well-Being as a Risk Factor for Depression: A Ten-Year Cohort Study. Journal of Affective Disorders, 122, 213-217. https://doi.org/10.1016/j.jad.2009.06.032

Wood, A. M., \& Tarrier, N. (2010). Positive Clinical Psychology: A New Vision and Strategy for Integrated Research and Practice. Clinical Psychology Review, 30, 819-829. https://doi.org/10.1016/j.cpr.2010.06.003

Wood, A. M., Linley, P. A., Maltby, J., Kashdan, T. B., \& Hurling, R. (2011). Using Personal and Psychological Strengths Leads to Increases in Well-Being over Time: A Longitudinal Study and the Development of the Strengths Use Questionnaire. Personality and Individual Differences, 50, 15-19. https://doi.org/10.1016/j.paid.2010.08.004

Woodworth, R. J., O’Brien-Malone, A., Diamond, M. R., \& Schüz, B. (2018). Data from, "Web-Based Positive Psychology Interventions: A Reexamination of Effectiveness". Journal of Open Psychology Data, 6, 1-6. https://doi.org/10.5334/jopd.35

World Health Organization (2017). Prevalence of Mental Disorders (n.d.). http://www.euro.who.int/en/health-topics/noncommunicable-diseases/mental-health/d ata-and-statistics

Wu, L., \& Koo, M. (2016). Randomized Controlled Trial of a Six-Week Spiritual Reminiscence Intervention on Hope, Life Satisfaction, and Spiritual Well-Being in Elderly with Mild and Moderate Dementia. International Journal of Geriatric Psychiatry, 31, 120-127. https://doi.org/10.1002/gps.4300

Zimmerman, M., McGlinchey, J. B., Posternak, M. A., Friedman, M., Attiullah, M., \& Boerescu, D. (2006). How Should Remission from Depression Be Defined? The Depressed Patient's Perspective. The American Journal of Psychiatry, 163, 148-150. https://doi.org/10.1176/appi.ajp.163.1.148 